\title{
Study of Digital Elevation Model (DEM) Extraction using Stereo Radargrammetry TerraSAR-X in Madiun Area - Elevation Accuracy Improvement
}

\author{
Inggit L. Sari ${ }^{1, *}$, Rachmat Maulana ${ }^{1, *}$, Haris S. Dyatmikd, Agus Suprijanto ${ }^{1}$ Rahmat Arief ${ }^{1}$ and Shadiq Ali ${ }^{1}$ \\ ${ }^{1}$ Remote Sensing Technology and Data Center, LAPAN, Pekayon, Jakarta, Indonesia
}

\begin{abstract}
High resolution images data from Terrasar-X are used to extract digital elevation model (DEM) using stereo radargrammetry in the attempt to achieve better resolution of terrain surface in Indonesia. As sample in this study, stereo pairs images from TerraSAR-X StripMap mode ( $\sim 3 \mathrm{~m}$ resolution) on Madiun city is used with difference of incidence angle around $\sim 18.88$ degree to extract the elevation of the area. Furthermore, field observation on the selected area will be used on elevation accuracy assessment. The digital surface elevation (DSM) generated by stereo radargrammetry in this study shows us high resolution with spatial pixel spacing 5.57 meter and elevation accuracy around $\sim 4$ meter.
\end{abstract}

\section{Introduction}

Synthetetic Aperature Radar (SAR) technology have been advanced through the years since its earliest day. This technology use radar as a means to observe the earth which means its not affected by clouds and time, in contrast to the optical remote sensing which affected by the clouds and only can works on day time when there's only sunlight.

On 2007, TerraSAR-X have been launched to the space carrying high frequency $\mathrm{X}$ band sensor, varying based on its imaging modes followed by TanDEM-X on 2010. TerraSAR-X resolution ranging around $1 \mathrm{~m}$ for its SpotLight mode to $40 \mathrm{~m}$ for Wide-ScanSAR mode. The most common mode on TerraSAR-X imagery is on its StripMap mode which have 3-meter resolution.[1]

Digital elevation model (DEM) is a digital representation of the Earth's relief that consist ordered array of elevations relative to a datum, and referenced to geographic coordinate. DEM can be distinguished by which representation on the elevation of earth surface, Digital surface model (DSM) is representing all feature on the earth surface like trees and houses while Digital Terrain model (DTM) representing the earth surface without all those features.

DEM has been a very important product on remote sensing imagery. The most used of DEM is on the process of orthorectification remote sensing image, be it as optical imagery or SAR imagery. Furthermore, its derivation can be applied on other area such as engineering works, agriculture, mining, or disaster management [2].

Stereo radargrammetry is traditional and mature approach on the elevation extraction from SAR imagery. The idea based on photogrammetry with its optical imagery while we use SAR imagery on its intensity (amplitude) to extract the elevation. As with the photogrammetry, stereo radargrammetry use two images (or more) with different incidence angles on the same area [3].

When a target is seen from different angles, the relief displacement on each SAR image will be different. The difference between the image coordinates of homologous points in a stereo pair is called parallax (leberl,1990). Each homologous point's parallax is relater to the corresponding ground target's height. When incidence angles of two sensors are constant, the target with larger parallax is higher than that with smaller parallax [4]. The optimized difference of this incident angle is ranging between $10^{\circ}-20^{\circ}[5]$ or $15^{\circ}-25^{\circ}[6]$.

The data we use is TerraSAR-X images which using $\mathrm{X}$ band on its mission. The elevation model we obtain will be a Digital Surface Model (DSM) which includes all features on earth surface as $\mathrm{X}$ band get backscattered at the top of any features on the earth surface.

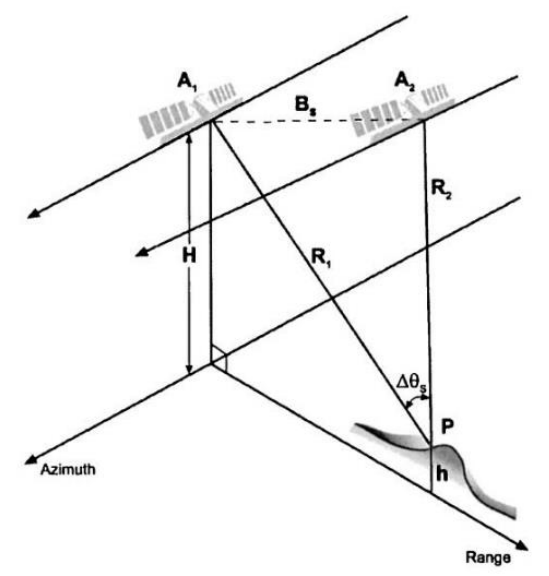

Fig. 1. Geometry of stereo-radargrammatry, $A$ and $H$ are the respective satellite position and altitude [7].

\footnotetext{
*Corresponding author: inggit.lolita@lapan.go.id, maularachmat@gmail.com
} 
Table 1. Characteristic of TerraSAR-X images pairs.

\begin{tabular}{|c|c|c|}
\hline & Image 1 & Image 2 \\
\hline Sensor & TerraSAR-X & TerraSAR-X \\
\hline Imaging Mode & StripMap & StripMap \\
\hline Acquisition time & $\begin{array}{l}24 / 03 / 2018 \\
22.22 .10- \\
22.22 .18\end{array}$ & $\begin{array}{l}10 / 04 / 2018 \\
22.13 .39- \\
22.13 .48\end{array}$ \\
\hline Product Type & SSC & SSC \\
\hline $\begin{array}{l}\text { Scene Centere } \\
\text { Incidence Angle }\end{array}$ & 28.765 & 47.653 \\
\hline Pass & Descending & Descending \\
\hline Side Look & Right & Right \\
\hline Polarization & $\mathrm{HH}$ & $\mathrm{HH}$ \\
\hline
\end{tabular}

\section{Study Area and Processing}

The study is carried out around Madiun City area, East Java. The characteristic of the surface relief of this area varies around agricultural lands, urban area, hills, and mountain. This elevation from this area ranges from 60 meters to 3265 meter while the maximum altitude is the peak of Lawu mountain.

Two TerraSAR-X images have been acquired on StripMap mode with $\mathrm{HH}$ polarization on Single-look Slant-range Complex (SSC). These images have sameside stereo pairs on descending orbits and have difference incidence angle of $\sim 18.88^{\circ}$ with 17 days acquisition interval.
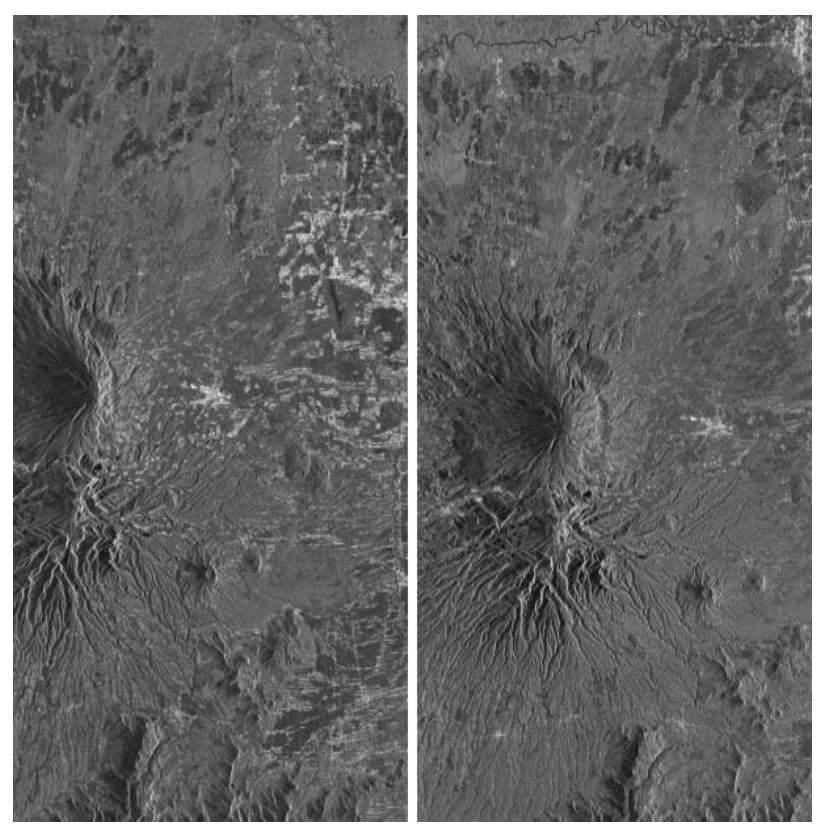

Fig. 2. Quick look of TerraSAR-X images pairs, taken at 24 March 2018 (left) and at 10 April 2018 (right).
The process of stereo radargrammetry is carried out automatically in order to achieve high precision and avoid manual interaction of the user. This is due to SAR images which are heavily distorted both radiometrically and geometrically by the terrain, such as shadow provided by slopes which facing away from the sensor. Furthermore, SAR images also contains random speckle noise which make the reduce the resolution or filter with the reference DEM to cope with this speckle noise [8].

The main idea of the stereo matching process is by retrieving a shift in pixel on range direction which is proportion.al to the topographic height. The shift then estimated by the means of co-registration between the two images using amplitude (intensity) cross correlation. This whole process is performed in pyramidal way as the estimating of initial shift is on the multi-looked 'then refining it iteration by iteration to obtain finer estimate.

Later on, these shifts are converted to height and geocoded into a map projection. The difference with basic geocoding procedure is that we applied the two antennae simultaneously in Range-Doppler equations. From there, we can obtain the height of each pixel and its location (Easting, Northing) in a given cartographic and geodetic reference system.

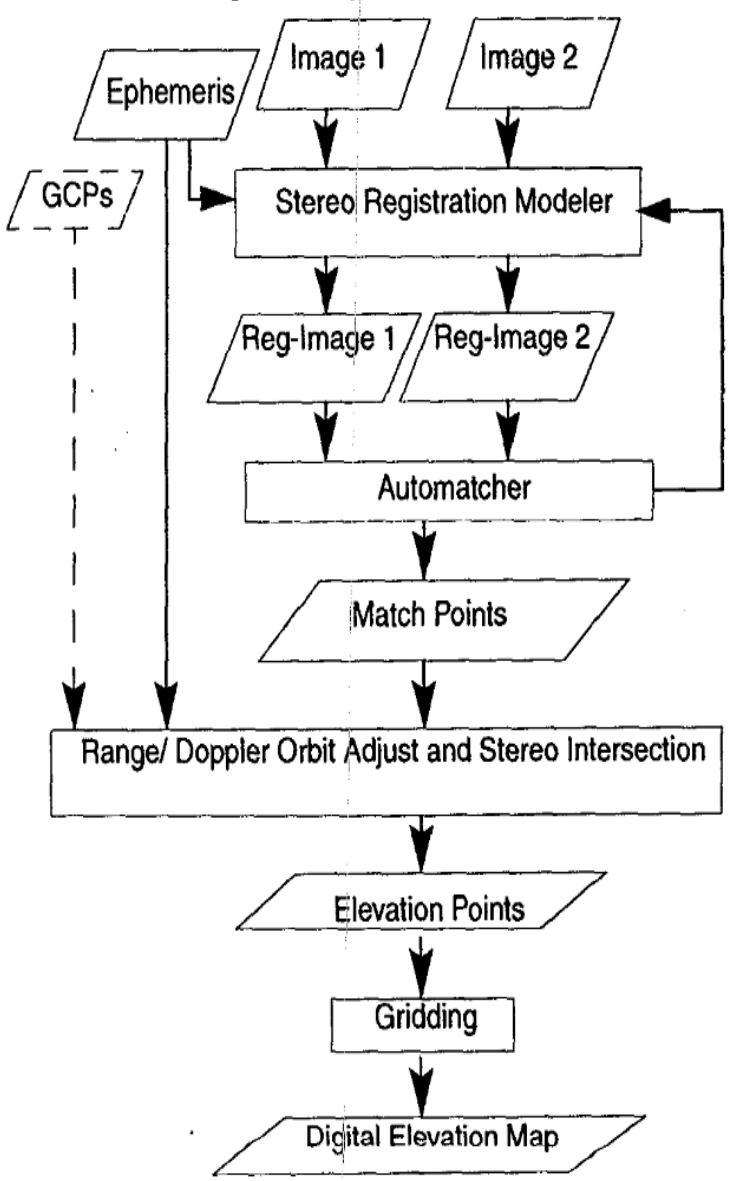

Fig. 3. Stereo radargrammetry processing flow chart [9]. 


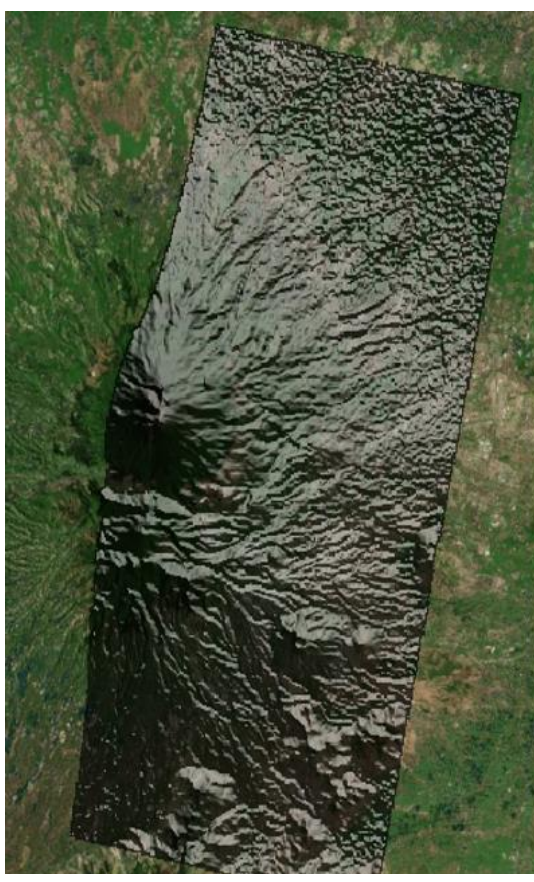

a

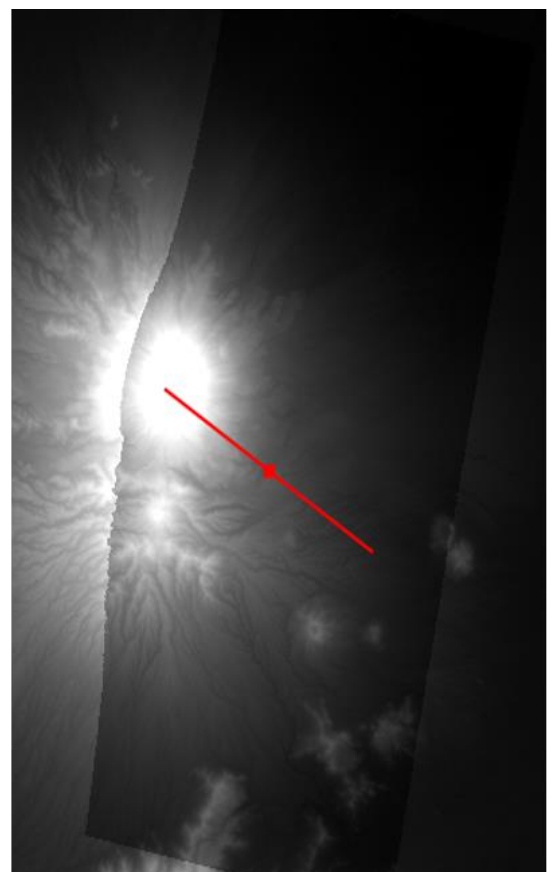

b

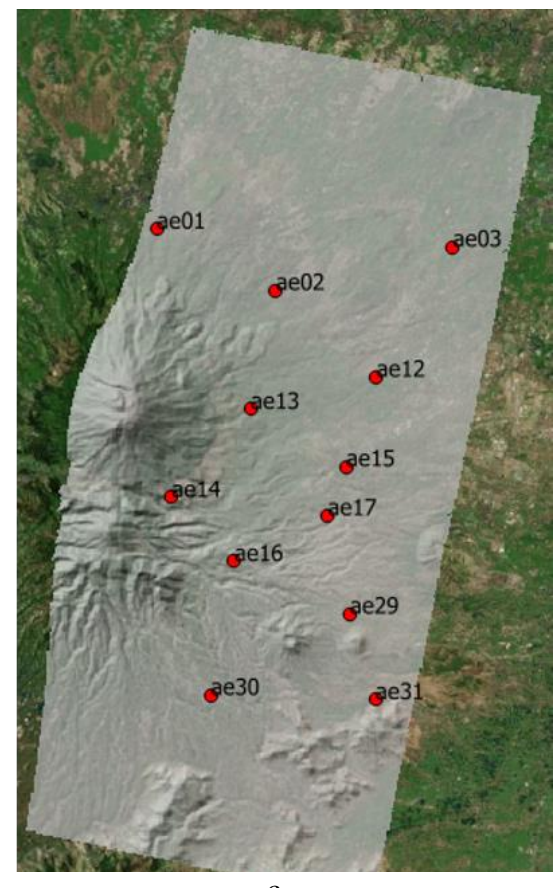

$\mathrm{c}$

Fig. 4. (a) Result of DSM stereo radargrammetry TerraSAR-X, (b) Elevation profile line of DSM stereo and DEMNAS (c) Distribution points of GPS field observation.

\section{Result and Discussion}

The results of Digital Surface Model (DSM) created using stereo-radargrammetry in our area of study have high resolution with spatial pixel spacing around 5.57 meter. Furthermore, we carried out elevation accuracy measurement by comparing the elevation of the stereo DSM result to field elevation observation using GNSS GPS of Garmin Geo 7X with accuracy of 0.05 meter. We also evaluate the results of stereo DSM in our study to national digital elevation model (DEMNAS Indonesia) provided by Indonesia Geospatial Agency (BIG) by taking elevation profile of these two DEM. The DEMNAS is produced from DSM of IFSAR TerraSAR$\mathrm{X}$ and ALOS-PALSAR with the accuracy improvement by processing addition of mass-points, spot-heights and break-line from topographic map using GMT-surface with tension $0.32[10]$.

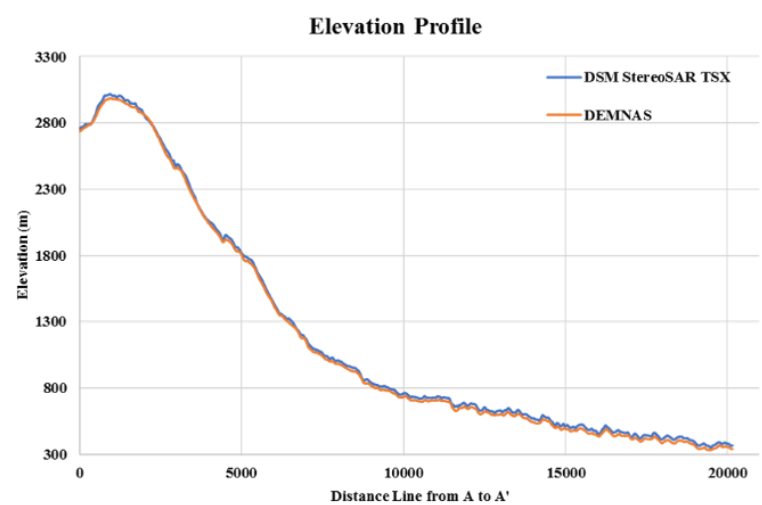

Fig. 5. Elevation profile between stereo radargrammetry DSM and DEMNAS, x-axis follow the red line on Fig. 4a with the elevation on the $y$-axis.
The elevation profile between the DSM stereo radargrammetry TerraSAR-X and DEMNAS can be seen at Fig. 5 where its elevation follows the red line on Fig. 4b. Based on both figures, the generated DSM has similar elevation profile with DEMNAS.

The elevation accuracy measurement of the DSM stereo radargarammetry TerraSAR-X using GPS field observation can be seen at Table 2 with respective points shown at Fig. 4c. The result from this measurement, we obtain the absolute mean height error of the DSM stereo radargrammetry is 3.676 meter and root mean square error is 4.018 meter with the standard deviation of error is 1.695 meter.

Table 2. Elevation accuracy measurement of stereo radargrammetry DSM with GPS field observation.

\begin{tabular}{|l|l|l|l|}
\hline Code No. & $\begin{array}{c}\text { GPS } \\
\text { Height }(\mathrm{m})\end{array}$ & $\begin{array}{c}\text { DSM } \\
\text { Height }(\mathrm{m})\end{array}$ & $\begin{array}{c}\text { Accuracy } \\
(\mathrm{m})\end{array}$ \\
\hline ae01 & 427.327 & 427.822 & 0.495 \\
\hline ae17 & 396.7880 & 390.772 & 6.016 \\
\hline ae02 & 300.5590 & 298.384 & 2.175 \\
\hline ae03 & 100.9570 & 105.676 & 4.719 \\
\hline ae31 & 249.4020 & 253.655 & 4.253 \\
\hline ae30 & 537.7290 & 542.123 & 4.394 \\
\hline ae29 & 357.1200 & 355.111 & 2.009 \\
\hline ae16 & 877.6850 & 879.378 & 1.693 \\
\hline ae15 & 388.4250 & 393.343 & 4.918 \\
\hline ae12 & 259.3960 & 264.910 & 5.514 \\
\hline ae13 & 647.8580 & 651.992 & 4.134 \\
\hline ae14 & 1321.6930 & 1317.897 & 3.796 \\
\hline
\end{tabular}




\section{Conclusion}

Digital Surface Model (DSM) generation using TerraSAR-X imagery in StripMap mode at Single-look Slant-range Complex (SSC) have been generated using stereo radargrammetry. The generated DSM have spatial resolution of 5.57 meter with elevation accuracy around $\sim 4$ meter. This proves that TerraSAR-X images capable of generating digital surface model (DSM) in stereo radargrammetry and show good result from it.

The authors would like to thank Remote Sensing Technology and Data Center, Indonesian National Institute of Aeronatics and Space (LAPAN) for providing TerraSAR-X data and for the support from Ministry of Research, Technology and Higher Education of the Republic of Indonesia (KEMENRISTEKDIKTI) through Reseach Incentives of National Innovation System (INSINAS) 2018 program.

\section{References}

1. DLR (German Aerospace Center). Basic Product Specification Document. Vol. 53, no. 1.9, p. 126 (2013).

2. A. Nascetti. High resolution radargrammetry: development and implementation of an innovative image matching strategy (2013).

3. M. Crosetto, F. Pérez. Radargrammetry and SAR interferometry for DEM generation: validation and data fusion. SAR Work. CEOS Comm. Earth Obs. Satell., no. 1, pp. 367-372 (2000).

4. T. Balz, X. He, L. Zhang, M. Liao. TerraSAR-X
Stereo Radargrammetry for precise DEM generation in south-east asia. Igarss 2014, no. 1, pp. 1-5 (2014).

5. N. d'Ozouville, B. Deffontaines, J. Benveniste, U. Wegmüller, S. Violette, G. de Marsily. DEM generation using ASAR (ENVISAT) for addressing the lack of freshwater ecosystems management, Santa Cruz Island, Galapagos. Remote Sens. Environ., vol. 112, no. 11, pp. 4131-4147 (2008).

6. S. D. Hennig, W. Koppe, N. Kiefl, J. Janoth. Digital Elevation Modeling Using Terrasar-X Stereo Pairs (2010).

7. T. Toutin, L. Gray. State-of-the-art of elevation extraction from satellite SAR data. ISPRS J. Photogramm. Remote Sens., vol. 55, no. 1, pp. 1333 (2000).

8. J. A. Ostrowski, P. Cheng. DEM Extraction from Stereo SAR Satellite Imagery. Geosci. Remote Sens. Symp. 2000. Proceedings. IGARSS 2000. IEEE 2000 Int., vol. 5, no. 819, pp. 2176-2178 (2000).

9. M. Marra, K. E. Maurice, D. C. Ghiglia, H. G. Frick. Automated DEM extraction using RADARSAT ScanSAR stereo data. IGARSS '98. Sens. Manag. Environ. 1998 IEEE Int. Geosci. Remote Sensing. Symp. Proceedings. (Cat. No.98CH36174), pp. 2351-2353 vol.5 (1998).

10. BIG (Indonesia Geospatial Information Agency). Seamless Digital Elevation Model (DEM) dan Batimetri Nasional. [Online]. Available: http://tides.big.go.id/DEMNAS/. [Accessed: 01Sep-2018]. 